\title{
Sudden Deafness: Is It Viral?
}

\author{
Saumil N. Merchant ${ }^{a, c}$ Marlene L. Durand ${ }^{b, d}$ Joe C. Adams ${ }^{a, c}$ \\ ${ }^{a}$ Department of Otolaryngology, Massachusetts Eye and Ear Infirmary, ${ }^{\mathrm{b}}$ Infectious Disease Unit, \\ Massachusetts Eye and Ear Infirmary and Massachusetts General Hospital, and Departments of \\ 'Otology and Laryngology and d Medicine, Harvard Medical School, Boston, Mass., USA
}

\section{Key Words}

Sudden deafness - Sensorineural hearing loss • Etiology • Pathology $\cdot$ Pathogenesis $\cdot$ Viral infection

\begin{abstract}
A number of theories have been proposed to explain the etiopathogenesis of idiopathic sudden sensorineural hearing loss (ISSHL), including viral infection, vascular occlusion, breaks of labyrinthine membranes, immune-mediated mechanisms and abnormal cellular stress responses within the cochlea. In the present paper, we provide a critical review of the viral hypothesis of ISSHL. The evidence reviewed includes published reports of epidemiological and serological studies, clinical observations and results of antiviral therapy, morphological and histopathological studies, as well as results of animal experiments. The published evidence does not satisfy the majority of the Henle-Koch postulates for viral causation of an infectious disease. Possible explanations as to why these postulates remain unfulfilled are reviewed, and future studies that may provide more insight are described. We also discuss other mechanisms that have been postulated to explain ISSHL. Our review indicates that vascular occlusion, labyrinthine membrane breaks and immune-mediated mechanisms are unlikely to be common causes of ISSHL. Finally, we review our recently proposed theory that abnormal cellular stress responses within the cochlea may be responsible for ISSHL.

Copyright $\odot 2008$ S. Karger AG, Basel
\end{abstract}

\section{KARGER}

Fax +41613061234

E-Mail karger@karger.ch

www.karger.com
(C) 2008 S. Karger AG, Basel

Accessible online at: www.karger.com/orl

\section{Introduction}

Idiopathic sudden sensorineural hearing loss (ISSHL) is a rather common otologic condition characterized by new onset of unilateral or bilateral sensorineural hearing loss that develops rather rapidly within minutes or hours. The entity was first described by De Kleyn in 1944 [1]. The etiology and pathogenesis of sudden deafness remain unknown. Proposed theories of causation include vascular occlusion [2], viral infection [3], breaks of labyrinthine membranes [4], immune-mediated mechanisms [5] and abnormal cellular stress responses within the cochlea [6]. A variety of medical and surgical therapies have been proposed and used for ISSHL over the past several decades, based on what etiology one believes is causative. Some of these therapies have resulted in significant morbidity and even mortality $[7,8]$. Therefore, elucidation of the etiology of this enigmatic entity is vital if progress is to be made in treating this condition. In this review, we provide a critical appraisal of the viral etiology. We describe gaps in our present state of knowledge and describe potential avenues for future research. We also discuss nonviral etiologies that have been proposed for ISSHL.

\section{Viral Hypothesis of ISSHL}

There are two potential mechanisms that have been proposed to explain how a viral infection can lead to ISSHL [reviewed by Wilson, 9]. One mechanism is viral

Saumil N. Merchant, MD

Massachusetts Eye and Ear Infirmary

243 Charles Street

Boston, MA 02114 (USA)

Tel. +1 617573 3503, Fax +1 617573 3939, E-Mail saumil_merchant@meei.harvard.edu 
invasion of the fluid spaces and/or soft tissues of the cochlea (cochleitis) or invasion of the cochlear nerve (neuritis). The virus is presumed to reach the inner ear via the hematogenous route, although other routes of spread are also possible such as from the cerebrospinal fluid (CSF) space or via the middle ear. The second mechanism is reactivation of a virus that is latent within tissues of the inner ear. It has been hypothesized that neurotropic viruses could infect the cochlear neurons, remain dormant for varying lengths of time, and then become reactivated later in life to result in a viral neuritis and/or cochleitis, leading to ISSHL. There is a third mechanism by which a virus could indirectly trigger ISSHL. This third mechanism involves a systemic or distant viral infection that triggers an antibody response that cross-reacts with an inner ear antigen (an example of the immune-mediated hypothesis) or that triggers a circulating ligand that causes pathologic activation of cellular stress pathways within the cochlea (an example of the stress response hypothesis). In this third scenario, we are not dealing strictly with a direct viral attack on the inner ear. The viral hypothesis of ISSHL, as proposed by various authors, implies the first two mechanisms, that is, a direct viral invasion of the inner ear or reactivation of a latent virus within the ear. In the discussion that follows in this paper, the viral hypothesis of ISSHL refers only to the first two mechanisms.

\section{Proof of Causation: The Henle-Koch Postulates}

The classic concepts of causation in infectious diseases as elaborated by Henle and Koch in the 1800s for bacterial and parasitic diseases have been adapted and modified for viral infections $[10,11]$. These postulates state that (1) a specific virus must be regularly present with the disease; (2) the virus must occur in an affected individual as the cause of the disease, rather than an incidental or accidental finding; and (3) one must show that the infection is transmissible by inoculation of material from a patient with the disease into a suitable experimental host $[10,11]$. In addition, a set of immunologic criteria have been developed for putative viral infections [11]. According to these criteria, immunologic proof of causation requires that (1) virus-specific antibody is absent prior to the illness; (2) antibody appears during the illness accompanied by presence of virus in appropriate tissues; (3) absence of antibody indicates susceptibility to disease; (4) presence of antibody indicates immunity to the disease; (5) production of the antibody by immunization prevents the disease. Exceptions to these postulates exist. The presence of antibodies does not indicate immunity to disease in many viral diseases, with HIV and hepatitis C serving as notable examples. In addition, many viral diseases are not due to primary viral infection, in which antibody seroconversion from negative to positive may be noted, but rather, are caused by reactivation of previously acquired but latent viruses. An example of this is cytomegalovirus (CMV) retinitis in immunocompromised patients, which is almost always due to reactivation of latent CMV rather than primary infection. It is helpful to keep these postulates in mind as we review the evidence concerning the viral hypothesis of ISSHL.

\section{Analysis of Evidence for and against the Viral Hypothesis}

Epidemiologic and Serologic Studies

Mumps virus has been reported to cause sudden deafness, based on clinical and serologic studies, the latter demonstrating seroconversion or the appearance of mumps IgM antibodies [12-17]. However, many of these same studies found that mumps accounted only for a small fraction (less than 10\%) of cases with ISSHL [1317]. Measles and rubella have also been temporally or serologically associated with a few cases of sudden deafness $[13,18]$. With widespread immunization against mumps, measles and rubella, the incidence of these diseases has fallen drastically, along with the near eradication of these agents as an etiological agent for ISSHL [19]. However, there has not been a concomitant decline in the incidence of ISSHL, further supporting the argument that these particular viruses are not the cause of most cases of ISSHL.

Members of the Herpesviridae family of viruses have been proposed as causes of ISSHL [9,20-22]. The herpesvirus family includes herpes simplex types 1 and 2, varicella-zoster virus (VZV), CMV, Epstein-Barr virus, human herpesvirus 6, 7 and 8 (HHV-6, HHV-7, HHV-8). All of these viruses, once acquired, persist in latent form lifelong. Most adults are seropositive for many of these viruses, having acquired them during childhood. For example, approximately $90 \%$ of adults are seropositive for HSV-1, 90\% for VZV, 70\% for CMV, 90\% for EBV, 95\% for HHV-6 [23]. They are, therefore, not susceptible to new (acute) infection from these viruses, and the hypothesis that ISSHL is caused by one of these viruses in a seropositive patient can only be explained by reactivation of latent virus. Unfortunately, there are no good serologic tests to diagnose reactivation. Once an individual is seropositive for a latent herpes virus, an increase in titer does not diagnose reactivation. An example of this is shingles, which represents a reactivation of latent infection due to VZV, a virus often acquired decades earlier. 
Shingles is not diagnosed by a rise in an already positive VZV antibody titer. Serologic studies of ISSHL that use increases in IgG titers for HSV or VZV, for example, in already seropositive patients as evidence of a causal relationship, offer little basis for this conclusion.

Other types of viruses such as respiratory viruses, adenovirues and arenaviruses have also been implicated in ISSHL, based on anamnestic or serological data $[3,13$, 19]. On the other hand, some studies have reported lack of increases in antibodies against multiple tested viruses [reviewed by Pitkäranta et al., 19]. In patients with ISSHL, Pitkäranta and Julkunen [24] could not detect production of interferon or interferon-induced gene expression in peripheral blood samples, both of which are useful diagnostic markers for systemic viral infections. Pitkäranta and Julkunen's study is unique and significant, because it did not target specific viruses, but rather, it assayed for sensitive markers of any systemic viral infection. Their study supports the argument that ISSHL is not commonly associated with a systemic viral infection.

\section{Clinical Studies Involving Antiviral Therapy}

Clinicians have used anti-herpes virus medications prescribed at the time of the hearing loss, either alone or in combination with corticosteroids, on an empirical basis. The problem with such therapy is the lack of adequate controls in most cases. Controls are especially important, because of the significant rate of spontaneous recovery of hearing in ISSHL. For example, in a prospective study of 166 cases over 5 years, Mattox and Simmons [25] reported that $65 \%$ of patients recovered their hearing, independent of any treatment.

The two antiviral drugs used most commonly, acyclovir and valacyclovir, are essentially the same drug. Valacyclovir is a prodrug of acyclovir that produces serum acyclovir levels that are 3-5 times as high as those achieved with oral acyclovir therapy, and similar to levels achieved by intravenous acyclovir. There have been at least four published, randomized, placebo-controlled, prospective clinical trials using acyclovir or valacyclovir [26-29]. However, none showed any benefit in using these drugs to treat ISSHL. Acyclovir or valacyclovir are active only against HSV or VZV. Therefore, the lack of efficacy supports the contention that HSV and VZV do not play a role in ISSHL, although it does not exclude the potential role of other viruses as being causative.

\section{Clinical Observations}

Hearing loss has frequently followed bacterial meningitis but not viral meningitis. In a study of meningitis and hearing loss, Nadol [30] found that hearing loss developed in $21 \%$ of 110 survivors of bacterial meningitis but in none of 304 patients with aseptic meningitis. Given the close communication between CSF and inner ear fluids, this lack of association argues against at least one specific group of viruses, the enteroviruses, as the etiology of ISSHL. Enteroviruses (e.g. coxsackievirus, echovirus, etc.) are the causative agents of $90 \%$ of cases of viral meningitis [31]. It also may argue for a different route of entry for viruses into the ear in ISSHL other than the CSF-perilymph (meningogenic) route. Nearly all cases of welldocumented mumps-induced sensorineural hearing loss, for example, do not occur after the rare cases of mumps meningoencephalitis but, rather, after mumps parotitis $[15-17,32,33]$. One could argue that ISSHL is caused by viruses that reach the ear only by the hematogenous route, for example.

Morphologic Evidence of Viruses in the Inner Ear

Westmore et al. [33] were able to isolate live mumps virus from the perilymph of a 26 -year-old woman who presented with ISSHL following mumps parotitis. This is the only report showing a direct role of a virus as a causal agent in ISSHL. Since negative results are generally not reported, one does not know how often investigators were unsuccessful in isolating viruses in the acute phase in patients with ISSHL.

\section{Histopathological Evidence}

A number of reports have described the histopathological findings in the temporal bones in patients who had ISSHL during life [7, 8, 34-44]. In all these studies, evidence of direct viral invasion or infection of the inner ear is lacking, such as isolation of virus from the labyrinth, demonstration of typical viral cytopathologic abnormalities, demonstration of viral particles by electron microscopy, or identification of specific viral antigens. Attempts have been made to look for viral nucleic acids (mainly HSV) in tissue sections of temporal bones with ISSHL using the polymerase chain reaction (PCR), but the results have been negative [Smith, pers. commun.].

It has been argued that ISSHL may be viral because the histopathological findings in temporal bones obtained from individuals with ISSHL are similar to changes observed in individuals who lost hearing while suffering from mumps, measles, rubella or herpes zoster (presumed viral labyrinthitis) [8]. In both sets of temporal bones (ISSHL and presumed viral labyrinthitis), the major changes observed are atrophy of hair cells and supporting cells of the organ of Corti, with variable lesions 
of other structures such as the stria vascularis, tectorial membrane, cochlear neurons, etc. There are potential problems with the line of reasoning that ISSHL is viral because of similarities between the two sets of temporal bones. First, in some cases, the association of sudden deafness with a systemic infection such as mumps was made on the basis of history and self-reporting by the patient many years after the event, which is potentially subject to error. Second, even if the patient had a true systemic viral illness and developed ISSHL, there is no proof of actual viral invasion of the ear. One could argue that the deafness was not due to a true viral labyrinthitis but rather on the basis of an immunologic or stress-induced response in the inner ear. Third, phenotypic similarity does not automatically imply similarity in causation. There are many examples of similar histopathological lesions caused by diverse etiologies. For example, loss of hair cells can be the result of a genetic mutation, noise trauma or ototoxic medications [42]. Finally, quantitative studies of temporal bones from patients with ISSHL and those who lost hearing following an attack of mumps, measles or herpes zoster showed significant differences in cochlear neuronal counts between the two groups, thus questioning whether the two groups are indeed similar [45].

Experimental Data from Studies in Animals

Many studies have been performed with direct inoculation of pathogenic viruses into the inner ears of experimental animals. These studies have not replicated the clinical or histopathological features observed in patients with ISSHL [45]. In many studies, experimental viral inoculation resulted in a progressive, rather than a sudden hearing loss and the histopathological findings within the cochlea were characterized by leukocytic infiltration, hemorrhage and widespread degeneration of sensory and neural structures followed by fibrosis and new bone formation in some cases [46-51]. In other studies, experimental inoculation of viruses into the labyrinth had little or no pathogenic effects [52-55]. Although patients do not succumb to sudden deafness, we have previously described one temporal bone in our collection that was acquired acutely during ISSHL [6]. This individual suffered a sudden and severe sensorineural hearing loss of $80-100$ $\mathrm{dB}$ and died 9 days after onset of deafness. Histopathology showed unusual and severe swelling of hair cells and supporting cells within the organ of Corti which was interpreted as the primary premortem pathologic change responsible for the sudden deafness. However, the temporal bone did not show any leukocytic invasion, hypervas- cular area or hemorrhage within the labyrinth as might be expected with a true viral cochleitis.

\section{Why Are the Henle-Koch Postulates Not Fulfilled for} the Viral Hypothesis of ISSHL?

The preceding review clearly demonstrates that the majority of postulates of causation described earlier remain unfulfilled with respect to a viral etiology of ISSHL, for which there are four possible explanations:

\section{Inaccessibility of the Cochlea during Life}

It is very difficult to gain access to cochlear tissue during life in order to test for morphologic presence of viruses. Surgical biopsy of intracochlear tissues is fraught with a high risk of permanent sensorineural hearing loss. An exploratory tympanotomy with sampling of inner ear fluid via the round or oval window without damaging the cochlea is possible, but this requires surgery, and it has not been accomplished to date on any regular basis.

\section{Paucity of Cochlear Tissue after Death}

Examination of cochlear tissue obtained at postmortem can provide material for investigation of a viral etiology for ISSHL. However, such material remains extremely sparse for a variety of reasons. Sudden deafness is not a fatal disorder. Therefore, autopsy studies often occur many years after the acute event that led to ISSHL. Another problem is that temporal bones are not routinely removed at the time of autopsy or routinely studied by general pathologists. Otopathology studies are performed in specialized laboratories typically in departments of otolaryngology, and only a handful of such laboratories remain active in world. These reasons, combined with the steep decline in the number of autopsies over the past several decades, has resulted in the procurement and study of only a miniscule number of temporal bones from patients who had ISSHL during life. For instance, temporal bone histopathology has been reported in the world literature in fewer than 50 cases of ISSHL, compared to the tens of thousands of clinical cases that occur annually.

\section{Technical and Scientific Limitations}

Some studies looking for evidence of a viral etiology for ISSHL have suffered from flaws in their design, as discussed earlier. Technical hurdles are evident in other cases. For example, the application of PCR to postmortem temporal bone tissue to look for evidence of viral genomic material is impeded by several factors such as postmortem autolysis, fragmentation of viral nucleic acids due to 
fixation and decalcification, and potential contamination of tissues from extraneous sources during processing [56].

\section{Viruses Do Not Cause ISSHL}

If the postulates of causation cannot be proven, then one has to entertain the explanation that ISSHL is not commonly the result of a viral infection.

\section{Conclusions Regarding the Viral Hypothesis and Future Studies}

There is reason to believe that infection with the mumps virus can lead to sudden deafness, based on the evidence reviewed above. However, it is also clear that such cases can only account for a small fraction of cases of ISSHL. The evidence to support the hypothesis that viral infections are a common cause of ISSHL is indirect and circumstantial. There is also evidence against viral causation, but again, this is not conclusive. It is evident, in light of the earlier discussion, that there are some very significant challenges when one attempts to investigate whether ISSHL is of viral etiology. Nevertheless, the potential exists for carefully designed investigations that may shed more definitive light on the subject.

\section{Epidemiologic and Serologic Studies}

Since many cases of ISSHL are immediately preceded by a presumed viral URI [3], specific epidemiologic and serologic studies to identify the etiology of the antecedent URI may be helpful. The common cold is most often caused by rhinovirus, which has 100 numbered serotypes, and by coronaviruses. In temperate parts of the eastern USA, the peak incidence of rhinovirus colds is in early fall, with a second (smaller) peak in spring, while colds from coronaviruses usually peak in winter months. A prospective population-based study could be devised to determine the incidence of ISSHL by month in the northeastern USA as well as the incidence of recent colds in these patients. If the incidence of recent colds in ISSHL patients were higher than in the local (control) population, this might suggest a role for one of the common cold viruses in ISSHL. If the peak incidence of ISSHL closely followed the peak incidence of rhinoviruses, a second study could be devised to search for a correlation with a particular serotype of rhinovirus in ISSHL.

\section{Studies of the Cochlea during the Acute Phase}

It may be possible to perform carefully planned studies of the inner ear in selected patients involving special imaging or tissue sampling of the cochlea during the acute phase of the illness. Examples include the application of sophisticated imaging techniques such as optical coherence tomography or confocal microscopy using middle ear probes placed through a myringotomy or exploratory tympanotomy. Such technology has the potential to provide images of the cochlea with detail approaching that of histological sectioning. Similarly, sampling of inner ear fluids using a round window labyrinthotomy performed in a minimally invasive manner may be feasible and safe, followed by application of PCR or mass spectrometry-based proteomics technology to assay for viral products. Such studies may be justified in patients at highest risk for permanent hearing loss.

\section{Temporal Bone Histopathology with Molecular}

Techniques

There is a potential for application of sophisticated techniques involving molecular biology to archival as well as prospectively acquired temporal bones from patients with ISSHL. Examples of such techniques include immunostaining for viral antigens, in situ PCR for viral nucleic acids and viral products, and novel methods to identify fragmented and short segments of nucleic acids (only 50-100 bp in length) such as that used to recently reconstruct the Neanderthal genome [57, 58].

\section{Other Etiologic Hypotheses for ISSHL}

\section{Vascular Theory}

Vascular occlusion or ischemia has been proposed as a mechanism for sudden deafness [2], based, in part, on the catastrophic nature of the event, which is similar to a thromboembolic stroke. However, many clinical, experimental and otopathological observations do not support a vascular etiology as a common cause of ISSHL. Thromboembolic events causing ISSHL would be expected to be more common in the elderly or those with peripheral vascular disease, which is not the case [25]. Further, ISSHL frequently occurs in young, healthy individuals. The labyrinthine artery, which supplies the cochlea and vestibular sense organs, is an end artery [42]. Therefore, it is difficult to explain cases of profound ISSHL without vertigo and preserved vestibular function on the basis of a vascular event. Experimental compromise of the blood supply of the cochlea results in irreversible hearing loss after $1 \mathrm{~h}$ of occlusion, even if blood flow is restored subsequently [59]. Patients with ISSHL can experience recovery of function days or weeks later, which argues against the vascular theory. Finally, both animal and human data 
have demonstrated that the hallmark of a vascular insult to the cochlea consists of deposition of connective tissue and new bone within the cochlea $[60,61]$. Connective tissue and new bone was observed in only one of 17 cases of ISSHL from our temporal bone collection [6] and has been reported in only 2 of 29 ears with ISSHL in the literature [35-44].

\section{Membrane Breaks}

A sudden break within the labyrinthine membranes of the cochlea with or without an accompanying rupture of the oval or round window membrane has been hypothesized to be the cause of ISSHL $[4,62,63]$. It is generally assumed that such breaks occur in response to sudden changes in intralabyrinthine pressures from physical exertion, the Valsalva maneuver, nose blowing, etc. It is further hypothesized that admixing of endolymph and perilymph at the site of the membrane break results in a generalized decrease in cochlear function, despite a very localized break.

There are several lines of argument to indicate that a break of labyrinthine membranes is not a common cause of ISSHL, including clinical, experimental and histopathological lines of evidence. The majority of patients presenting clinically with ISSHL do not describe a precipitating physical event leading to the hearing loss. Indeed, many patients report experiencing deafness upon awakening or while being sedentary [25]. Furthermore, individuals who are subjected to physical exertion with high intracranial and intra-abdominal pressures such as women in childbirth, weight lifters, etc., do not experience an increased incidence of ISSHL. Middle ear exploration, which used to be commonly performed in patients with ISSHL for presumed oval or round window ruptures, has been largely given up in the USA, in part because of negative results. There is also evidence from animal experimentation and temporal bone histopathological data such as from patients with Ménière's syndrome that localized breaks in labyrinthine membranes and fistulae of the cochlear duct do not result in widespread cochlear dysfunction [42]. There have been three human temporal bone case reports attributing ISSHL to a rupture of cochlear membranes [40,41]. The history of one of these cases showed a documented, fluctuating, lowfrequency hearing loss, rather than ISSHL. The second case had a hearing loss documented at the age of 68 , but there was no indication that this was, in fact, a sudden loss. In the third case, the interpretation of the histopathology on one side was confounded by the fact that the patient had undergone a labyrinthectomy during life.
Other authors who have examined temporal bones from patients with ISSHL have not found evidence of active or healed ruptures of the oval or round windows, basilar membrane or Reissner's membrane $[6,8,44]$.

\section{Immunologic Theory}

The immunologic hypothesis of ISSHL is based on circulating antibodies cross-reacting with inner antigens $[5,64,65]$ or activated $T$ cells damaging the inner ear [65]. Such antibodies could conceivably be triggered by viruses or other agents. Such antibodies have also been proposed as being responsible for so-called autoimmune inner ear disease. A number of putative inner ear antigens have been proposed as targets of such antibodies, including type 2 collagen [66], $\beta$-actin [67], cochlin $[68,69]$, and $\beta$-tectorin [69]. The best documented of these candidate antibodies is to choline transporter-like protein 2 (CTL2) [70]. Out of a group of 20 patients with ISSHL, 9 were found to have antibodies against CTL2 [71]. Antibodies directed against CTL2 were reported to produce hearing loss in guinea pigs when expressed via a hybridoma growing in mice [72] or when administered by intracochlear infusion [73]. However, only 3 of 6 animals whose cochleae were perfused with $1 \mathrm{mg} / \mathrm{ml}$ of affinity-purified antibody showed a hearing loss. It seems unlikely that antibody titers this high would be present in perilymph of patients with ISSHL. Further, unlike what is seen in patients with ISSHL, the hearing loss in these animals developed over a span of days, rather than suddenly.

The functions of a great many proteins have been shown to be impeded by antibodies that block their function, but the ability of an antibody to block protein function is only a small part of showing that there may be a corresponding immunological disorder. Problems faced by arguments for any given antibody contributing to ISSHL include: the need for large-scale, blinded assays for the putative antibody in humans with no hearing problems to show that patients with ISSHL truly are immunologically different from the general population, the need to show that putative antibody titers change in synchrony with the hearing states of patients, and the need to show the presence of effective levels of the putative antibody within the cochleae of patients with ISSHL. It should be kept in mind that the primary basis for considering ISSHL as being immune-mediated is its responsiveness to steroids. This view overlooks the fact that anti-inflammatory steroids are known to have a wide range of effects on multiple, nonimmune, bodily processes. Consideration of nonimmune cochlear processes that are steroid re- 
sponsive may raise interesting new possibilities for explaining ISSHL, as discussed below.

\section{Stress Response Theory}

The stress response hypothesis states that ISSHL may be the result of abnormal activation of cellular stress pathways within the cochlea involving transcription factors such as nuclear factor- $\kappa \mathrm{B}(\mathrm{NF \kappa} \mathrm{B})$ [6]. Pathological activation of NFKB can result in production of inflammatory cytokines and other stress-related proteins that can disrupt the homeostatic balance of a cell or tissue, and can account for the sudden and often catastrophic nature of ISSHL. NFKB is present in significant amounts in specific tissues within the cochlea such as the supporting cells of the organ of Corti, spiral limbus and spiral ligament [74].

We hypothesize that many different events could trigger an abnormal stress response in the ear, resulting in ISSHL. Examples of triggering events include a systemic viral illness, a systemic inflammatory disorder, and physical, mental or metabolic stress. These various triggers could result in the production of circulating ligands such as cytokines or reactive oxygen species that result in pathological activation of NFKB within the cochlea.

The cellular stress response hypothesis can account for many of the observed clinical and histopathological features of ISSHL. Transient activation of the system may result in spontaneous recovery of hearing, whereas severe disruption can account for irreversible damage and permanent hearing loss. It is well established that corticosteroids are effective inhibitors of $\mathrm{NF \kappa B}$, which is consistent with the clinical response to steroids observed in patients with this disorder. The stress response hypothesis can account for the lack of beneficial effect of antiviral medications in sudden deafness, because actual viral invasion of the cochlea does not have to occur to activate $\mathrm{NF \kappa B}$, even in cases where the hearing loss may have been triggered by a viral systemic illness. The hypothesis can also explain the histopathological abnormalities reported in ISSHL, such as that observed acutely in the one temporal bone obtained 9 days after onset of sudden deafness [6], and the observation that the predominant chronic abnormality is atrophy of the organ of Corti.

One prominent clinical observation is that ISSHL is often unilateral. It is possible that a circulating ligand can trigger activation of NFKB mainly in one ear. We have found that intraperitoneal injection of lipopolysaccharide endotoxin consistently resulted in activation of $\mathrm{NF \kappa B}$ in type II fibrocytes of the spiral ligament in the mouse, but curiously, the activation was nearly always asymmetric between the two ears [unpubl. obs. in over 30 animals]. Our hypothesis is that cochlear NFкB was activated by circulating cytokines that were produced by peritoneal cells in response to the lipopolysaccharide. Although the cellular mechanisms that underlie asymmetric activation remain unknown, these findings support the notion of asymmetric activation of cochlear NFKB in response to systemic perturbation. Our preliminary attempts to induce hearing loss with systemic lipopolysaccharide administration have been unsuccessful. Nevertheless, the reliability of the asymmetric cochlear activation indicates that systemic events can induce asymmetric disturbances within the inner ear. Type II fibrocytes are a key component of the potassium ion recirculation system of the cochlea $[75,76]$ and their integrity is essential for maintenance of high endolymphatic potassium ion levels that are necessary for sensory cell function. Our hypothesis is that a 'second hit' upon the system, in addition to the stress evidenced by NFкB activation in type II fibrocytes, is necessary to incapacitate the cells and produce a hearing loss.

\section{Conclusions}

We reviewed the proposed theories of causation of ISSHL, with an emphasis on the viral hypothesis. We analyzed published evidence for and against the various theories. The evidence indicates that viral and vascular etiologies can, in some cases, lead to sudden deafness. However, the published evidence does not support the idea that viral or vascular etiologies are common causes of ISSHL. The evidence for membrane breaks and immunological causation of ISSHL is weak. We also reviewed an interesting and new hypothesis that ISSHL may be the result of pathologic activation of cellular stress pathways within the cochlea. Future research to elucidate the precise etiopathogenesis of this condition is vital if progress is to be made in its treatment.

\section{Acknowledgements}

Supported in part by NIH grant U24 DC008559 (Human Temporal Bone Consortium for Research Resource Enhancement). We also thank Mr. Axel Eliasen and Mr. Lakshmi Mittal for support of this work. 


\section{References}

1 De Kleyn A: Sudden complete or partial loss of function of the octavus-system in apparently normal persons. Acta Otolaryngol (Stockh) 1944;32:407-429.

2 Rasmussen H: Sudden deafness. Acta Otolaryngol 1949;37:65-70.

3 van Dishoeck H, Bierman T: Sudden perceptive deafness and viral infection (report of the first one hundred patients). Ann Otol Rhinol Laryngol 1957;66:963-980.

4 Simmons FB: Theory of membrane breaks in sudden hearing loss. Arch Otolaryngol 1968; 88:41-48.

5 Veldman JE: Cochlear and retrocochlear immune-mediated inner ear disorders. Pathogenetic mechanisms and diagnostic tools. Ann Otol Rhinol Laryngol 1986;95:535540.

6 6 Merchant SN, Adams JC, Nadol JB: Pathology and pathophysiology of idiopathic sudden sensorineural hearing loss. Otol Neurotol 2005;26:151-160.

7 Schuknecht HF, Kimura RS, Naufal PM: The pathology of sudden deafness. Acta Otolaryngol (Stockh) 1973;76:75-97.

-8 Schuknecht HF, Donovan ED: The pathology of idiopathic sudden sensorineural hearing loss. Arch Otorhinolaryngol 1986;243: $1-15$.

$\checkmark 9$ Wilson WR: The relationship of the herpesvirus family to sudden hearing loss: a prospective clinical study and literature review. Laryngoscope 1986;96:870-877.

10 Rivers TM: Viruses and Koch's postulates. J Bacteriol 1937;33:1.

-11 Evans AS: Causation and disease: the HenleKoch postulates revisited. Yale J Biol Med 1976;49:175-195.

12 Vuori M, Lahikainen EA, Peltonen T: Perceptive deafness in connection with mumps. A study of 298 servicemen suffering from mumps. Acta Otolaryngol 1962;55:231-236.

13 Veltri RW, Wilson WR, Sprinkle PM, Rodman SM, Kavesh DA: The implication of viruses in idiopathic sudden hearing loss: primary infection or reactivation of latent viruses? Otolaryngol Head Neck Surg 1981; 89:137-141

14 Yanagita N, Murahashi K: A comparative study of mumps deafness and idiopathic profound sudden deafness. Arch Otorhinolaryngol 1986;243:197-199.

15 Nomura Y, Harada T, Sakata H, Sugiura A: Sudden deafness and asymptomatic mumps. Acta Otolaryngol Suppl 1988;456:9-11.

- 16 Nomura Y, Harada T, Hara M: Viral infection and the inner ear. ORL J Otorhinolaryngol Relat Spec 1988;50:201-211.

17 Okamoto M, Shitara T, Nakayama M, Takamiya H, Nishiyama K, Ono Y, Sano H: Sudden deafness accompanied by asymptomatic mumps. Acta Otolaryngol Suppl 1994;514 $45-48$.
18 Kobayashi H, Suzuki A, Nomura Y: Unilateral hearing loss following rubella infection in an adult. Acta Otolaryngol Suppl 1994; 514:49-51.

19 Pitkäranta A, Vasama JP, Julkunen I: Sudden deafness and viral infections. Otorhinolaryngol Nova 1999;9:190-197.

20 Koide J, Yanagita N, Hondo R, Kurata T: Serological and clinical study of herpes simplex virus infection in patients with sudden deafness. Acta Otolaryngol Suppl 1988;456: 21-26.

21 Fukuda S, Furuta Y, Takasu T, Suzuki S, Inuyama $Y$, Nagashima K: The significance of herpes viral latency in the spiral ganglia. Acta Otolaryngol Suppl 1994;514:108-110.

22 Takasaki T, Higashikawa M, Motoyama S, Sugita K, Kurane I: Serum antibodies to human herpesvirus 7 , human herpesvirus 6 and cytomegalovirus in patients with idiopathic facial nerve palsy or sudden deafness. J Laryngol Otol 1998;112:617-621.

23 Straus SE: Introduction to Herpesviridae; in Mandell GL, Bennett JE, Dolin R (eds): Mandell, Douglas and Bennett's Principles and Practice of Infectious Diseases, ed 6. Philadelphia, Elsevier Churchill Livingstone, 2005, pp 1756-1761.

24 Pitkäranta A, Julkunen I: Sudden deafness: lack of evidence for systemic viral infection. Otolaryngol Head Neck Surg 1998;118:397399.

25 Mattox DE, Simmons FB: Natural history of sudden sensorineural hearing loss. Ann Otol Rhinol Laryngol 1977;86:463-480.

26 Stokroos RJ, Albers FW, Tenvergert EM: Antiviral treatment of idiopathic sudden sensorineural hearing loss: a prospective, randomized, double-blind clinical trial. Acta Otolaryngol 1998;118:488-495.

27 Tucci DL, Farmer JC Jr, Kitch RD, Witsell DL: Treatment of sudden sensorineural hearing loss with systemic steroids and valacyclovir. Otol Neurotol 2002;23:301-308.

28 Westerlaken BO, Stokroos RJ, Wit HP, Dhooge IJM, Albers FWJ: Treatment of idiopathic sudden sensorineural hearing loss with antiviral therapy: a prospective, randomized, double-blind clinical trial. Ann Otol Rhinol Laryngol 2003;112:993-1000.

29 Uri N, Doweck I, Cohen-Kerem R, Greenberg E: Acyclovir in the treatment of idiopathic sudden sensorineural hearing loss. Otolaryngol Head Neck Surg 2003; 128:544549.

30 Nadol JB Jr: Hearing loss as a sequela of meningitis. Laryngoscope 1978;88:739-755.

31 Modlin JF: Coxsackieviruses, echoviruses, and newer enteroviruses; in Mandell GL, Bennett JE, Dolin R (eds): Mandell, Douglas, and Bennett's Principles and Practice of Infectious Diseases, ed 6. Philadelphia, Elsevier Churchill Livingstone, 2005, pp 21482161.
- 32 Azimi PH, Cramblett HG, Haynes RE: Mumps meningoencephalitis in children. JAMA 1969;207:509-512.

33 Westmore GA, Pickard BH, Stern H: Isolation of mumps virus from the inner ear after sudden deafness. BMJ 1979;1:14-15.

34 Schuknecht HF, Benitez J, Beekhuis J, Igarashi $\mathrm{M}$, Singleton G, Ruedi L: The pathology of sudden deafness. Laryngoscope 1962;72: 1142-1157.

-35 Beal DD, Hemenway WG, Lindsay JR: Inner ear pathology of sudden deafness. Arch Otolaryngol 1967;85:591-598.

36 Gussen R: Sudden deafness of vascular origin: a human temporal bone study. Ann Otol Rhinol Laryngol 1976;85:94-100.

-37 Nomura Y, Hiraide F: Sudden deafness: a histopathological study. J Laryngol Otol 1976;90:1121-1142.

38 Ishii T, Toriyama M: Sudden deafness with severe loss of cochlear neurons. Ann Otol Rhinol Laryngol 1977;86:541-548.

- 39 Sando I, Harada T, Loehr A, Sobel JH: Sudden deafness: histopathologic correlation in temporal bone. Ann Otol Rhinol Laryngol 1977;86:269-279.

40 Gussen R: Sudden hearing loss associated with cochlear membrane rupture. Arch Otolaryngol 1981;107:598-600.

41 Gussen R: Sudden deafness associated with bilateral Reissner's membrane ruptures. Am J Otolaryngol 1983;4:27-32.

42 Schuknecht HF: Pathology of the Ear, ed 2. Philadelphia, Lea and Febiger, 1993, p 672.

-43 Yoon TH, Paparella MM, Schachern PA, Alleva M: Histopathology of sudden hearing loss. Laryngoscope 1990;100:707-715.

44 Vasama JP, Linthicum FH Jr: Idiopathic sudden sensorineural hearing loss: temporal bone histopathologic study. Ann Otol Rhinol Laryngol 2000;109:527-532.

45 Khetarpal U, Nadol JB Jr, Glynn RJ: Idiopathic sudden sensorineural hearing loss and postnatal viral labyrinthitis: a statistical comparison of temporal bone findings. Ann Otol Rhinol Laryngol 1990;99:969-976.

46 Woolf NK, Harris JP, Ryan AF, Butler DM, Richman DD: Hearing loss in experimental cytomegalovirus infection of the guinea pig inner ear: prevention by systemic immunity. Ann Otol Rhinol Laryngol 1985;94:350356.

47 Nomura Y, Kurata T, Saito K: Cochlear changes after herpes simplex virus infection. Acta Otolaryngol 1985;99:419-427.

-48 Tanaka K, Fukuda S, Suenaga T, Terayama Y: Experimental mumps virus-induced labyrinthitis: immunohistochemical and ultrastructural studies. Acta Otolaryngol Suppl (Stockh) 1988;456:98-105.

49 Harris JP, Fan JT, Keithley EM: Immunologic responses in experimental cytomegalovirus labyrinthitis. Am J Otolaryngol 1990;11: 304-308. 
-50 Tamura M, Ogino S, Matsunaga T, Asada H, Kondo K, Kurata T, Yamanishi K: Experimental labyrinthitis in guinea pigs caused by a hantavirus. ORL J Otorhinolaryngol Relat Spec 1991;53:1-5.

51 Stokroos RJ, Albers FWJ, Schirm J: The etiology of idiopathic sudden sensorineural hearing loss: experimental herpes simplex virus infection of the inner ear. Am J Otol 1998;19: 447-452.

-52 Karmody CS: Viral labyrinthitis. An experimental study. Ann Otol Rhinol Laryngol 1975;84:179-181.

53 Davis LE, Johnson RT: Experimental viral infections of the inner ear. I. Acute infections of the newborn hamster labyrinth. Lab Invest 1976;34:349-356.

54 Davis GL: In vitro models of viral-induced congenital deafness. Am J Otol 1981;3:156160.

-55 Tanaka K, Hirai T, Suenaga T, Terayama Y, Fukuda S, Matsumiya H: Experimental Sendai virus-induced labyrinthitis in guinea pigs: an ultrastructural study of cochlear lesions. Ann Otol Rhinol Laryngol 1984;93: 240-246.

-56 McKenna MJ, Kristiansen AG, Tropitzsch A, Tranebjærg L, Merchant SN: Deoxyribonucleic acid contamination in archival human temporal bones - a potentially significant problem. Otol Neurotol 2002;23:789-792.

-57 Noonan JP, Coop G, Kudaravalli S, Smith D, Krause J, Alessi J, Chen F, Platt D, Paabo S, Pritchard JK, Rubin EM: Sequencing and analysis of Neanderthal genomic DNA. Science 2006;314:1113-1118.

-58 Green RE, Krause J, Ptak SE, Briggs AW, Ronan MT, Simons JF, Du L, Egholm M, Rothberg JM, Paunovic M, Paabo S: Analysis of one million base pairs of Neanderthal DNA. Nature 2006;444:330-336.
Perlman HB, Kimura RS, Fernandez C: Experiments on temporary occlusion of the internal auditory artery. Laryngoscope 1959; 69:591-613.

60 Perlman HB, Kimura R: Experimental obstruction of the venous drainage and arterial supply of the inner ear. Ann Otol Rhinol Laryngol 1957;66:537-546.

61 Belal A: The effects of vascular occlusion on the human inner ear. J Laryngol Otol 1979; 93:955-968.

62 Goodhill V: Labyrinthine membrane ruptures in sudden sensorineural hearing loss. Proc R Soc Med 1976;69:565-572.

63 Simmons FB: The double membrane break syndrome in sudden hearing loss. Laryngoscope 1979;89:59-66.

64 Veldman JE, Hanada T, Meeuwsen F: Diagnostic and therapeutic dilemmas in rapidly progressive sensorineural hearing loss and sudden deafness. Acta Otolaryngol (Stockh) 1993;113:303-306.

-65 García Berrocal JR, Ramírez-Camacho R: Sudden sensorineural hearing loss: supporting the immunologic theory. Ann Otol Rhinol Laryngol 2002;111:989-997.

66 Yoo TJ, Tomoda K, Hernandez AD: Type II collagen-induced autoimmune inner ear lesions in guinea pigs. Ann Otol Rhinol Laryngol Suppl 1984;113:3-5.

67 Boulassel MR, Tomasi JP, Deggouj N, Gersdorff M: Identification of beta-actin as a candidate autoantigen in autoimmune inner ear disease. Clin Otolaryngol Allied Sci 2000;25: 535-541.

68 Boulassel MR, Deggouj N, Tomasi JP, Gersdorff $\mathrm{M}$ : Inner ear autoantibodies and their targets in patients with autoimmune inner ear diseases. Acta Otolaryngol 2001;121:2834.

69 Solares CA, Edling AE, Johnson JM, Baek MJ, Hirose K, Hughes GB, Tuohy VK: Murine autoimmune hearing loss mediated by CD4+ T cells specific for inner ear peptides. J Clin Invest 2004;113:1210-1217.
70 Nair TS, Kozma KE, Hoefling NL, Kommareddi PK, Ueda Y, Gong TW, Lomax MI, Lansford CD, Telian SA, Satar B, Arts HA, El-Kashlan HK, Berryhill WE, Raphael Y, Carey TE: Identification and characterization of choline transporter-like protein 2, an inner ear glycoprotein of 68 and $72 \mathrm{kDa}$ that is the target of antibody-induced hearing loss. J Neurosci 2004;24:1772-1779.

71 Disher MJ, Ramakrishnan A, Nair TS, Miller JM, Telian SA, Arts HA, Sataloff RT, Altschuler RA, Raphael Y, Carey TE: Human autoantibodies and monoclonal antibody KHRI-3 bind to a phylogenetically conserved inner-ear-supporting cell antigen. Ann NY Acad Sci 1997;830:253-265.

-72 Nair TS, Raphael Y, Dolan DF, Parrett TJ, Perlman LS, Brahmbhatt VR, Wang Y, Hou X, Ganjei G, Nuttall AL, Altschuler RA, Carey TE: Monoclonal antibody induced hearing loss. Hear Res 1995;83:101-113.

-73 Nair TS, Prieskorn DM, Miller JM, Mori A, Gray J, Carey TE: In vivo binding and hearing loss after intracochlear infusion of KHRI-3 antibody. Hear Res 1997;107:93101.

74 Adams JC: Clinical implications of inflammatory cytokines in the cochlea: a technical note. Otol Neurotol 2002;23:316-322.

75 Kikuchi T, Kimura RS, Paul DL, Adams JC: Gap junctions in the rat cochlea: immunohistochemical and ultrastructural analysis. Anat Embryol (Berl) 1995;191:101-118.

-76 Kikuchi T, Kimura RS, Paul DL, Takasaka T, Adams JC: Gap junction systems in the mammalian cochlea. Brain Res Brain Res Rev 2000;32:163-166.

\section{Comments}

J.R. García-Berrocal: The critical review presented by the authors states the lack of evidence for any etiology for SSHL, including the viral infection. Although viral and vascular etiologies were classically suggested, inner ear membrane breaks and more recently immune-mediated mechanisms have been added. Efforts to assign either etiology may be conceptually wrong based on current knowledge since the implication of diverse etiopathogenetic factors in suddenly presenting cochleovestibular damage has been proven. Thus, an immune reaction could be triggered by a virus, leading to vasculitis and lymphocyte recruitment to the inner ear. However, until advances in technology allow us to identify viruses in vivo in inner ear fluids without causing irreparable damage, as well as to confirm the direct cytopathic effects of viral infection in the cochlea, the application of immunological and serological studies will continue to provide a presumptive diagnosis in some patients with sensori- 
neural hearing loss. Otherwise, authors consider an attractive hypothesis that states that idiopathic sudden deafness (SD) may be induced by activation of cellular stress inside the cochlea. Triggering events such as a systemic viral illness, a systemic inflammatory disorder and physical, mental or metabolic stress have been previously involved as predisposing risk factors in the development of SD. Stressors modulate immune function; after initiation of a psychological or physical stressor, a transient increase in the number of CD8 and natural killer lymphocytes is observed [1]. Chronic stress decreases CD8 T cells, contributing to the increase in viral infectious diseases (increased susceptibility to infection or to activation of latent infection) because the CD8 population is a critical defense against viral infections [2]. During an immune response, the nervous and the immune system interact and this interaction is essential for maintaining homeostasis, even under stressful stimulation/challenge. Hence, stress has a significant impact upon the activity of the immune response. Cortisol, the end product of the hypothalamic-pituitary-adrenal (HPA) axis, is produced and secreted in stress and is capable of decreasing proinflammatory activities by inhibiting type 1 immunological pathways (thereby favoring type 2 activities). Further, under stimulation the catecholamine norepinephrine, an effector of the sympathetic nervous system (SNS), is released from the sympathetic nerve terminals in lymphoid organs and the target immune cells express adrenoreceptors. Through stimulation of these receptors, norepinephrine affects lymphocyte traffic, circulation and proliferation, and it modulates cytokine production and the functional activity of different lymphoid cells. Catecholamines also inhibit the production of type 1 proinflammatory cytokines, where they stimulate the production of type 2 - mainly anti-inflammatory cytokines - and various types of antibodies [3]. Therefore, the activation of stress response components - mainly the SNS - during an immune response may have proinflammatory consequences as well. Stress/stressors (bacterial and viral infections, free radicals, oxidative stress) and basic stress response functions (HPA axis and SNS activity) involve the stimulation of stress-sensitive heat shock protein production/gene expression and NFKB activation. The nuclear transcription factor $\mathrm{NF \kappa B}$ triggers the activation of a large number of genes in response to inflammation, viral and bacterial infections and other stressful situations. Proinflammation involves complex pathways that include stress response, heat shock protein, NFкB, iNOS and free radical activation/induction and may represent an underlying concept that contributes to the onset and progression of various disease processes [3]. Thereby, the stress response theory could represent a common etiopathogenetic pathway for the main etiologies suggested for SD. Likewise, this hypothesis provides a main role to type II fibrocytes and supporting cells of the organ of Corti. In this respect, we fully agree with the authors since these cells should be a critical target of any treatment for inner ear disorders [4]. However, further research must be performed in order to clarify clinical situations in which patients with a stress-induced SD do not improve their hearing after corticosteroid therapy and situations in which the hearing loss is not reversed after such a treatment in patients with an autoinflammatory disease [unpubl., pers. obs.].

\section{References}

1 Herbert TB, Cohen S, Marsland AL, Bachen EA, Rabin BS, Muldoon MF, Manuck SB: Cardiovascular reactivity and the course of immune response to an acute psychological stressor. Psychosom Med 1994;56: 337-344.

2 Rabin BS: Effect of stress on immune function, allergy and health. Curr Opin Otolaryngol Head Neck Surg 2000;8:234-238.

3 Esch T, Stefano GB: Proinflammation: a common denominator or initiator of different pathophysiological disease processes. Med Sci Monit 2002;8:HY1-HY9.

4 Ramírez-Camacho R, García-Berrocal JR, Trinidad A, González-García JA, Verdaguer JM, Ibáñez A, Rodríguez A, Sanz R: Central role of supporting cells in cochlear homeostasis and pathology. Med Hypotheses 2006;67:550-555.

T. Linder: Saumil Merchant and his colleagues very elegantly listed the pros and cons of a viral etiopathogenesis for sudden sensorineural hearing loss (SNHL). Except for mumps virus, there are few other viral pathogens known which could consistently induce a unilateral SNHL [see the article by Oliveira et al., this issue, pp. 42-51]. Their arguments clearly illustrate the fact, that viral inflammation of the inner ear or cochlear nerve is very unlikely in SNHL. Even 1.5- and 3-tesla MRI scans performed within days of the acute onset could not verify signs of inflammation, ischemia or bleeding as a possible incident. Therefore, it is mandatory to look for other etiologies and they have come up with an interesting theory of 'stress'-induced activation of NFкB within the cochlea. However, in their membrane-rupture section they state that 'Indeed, many patients report experiencing deafness upon awakening or while being sedentary' with no consistent relation to known stress factors within the body. Also the unilaterality of SNHL needs to be further addressed in their theory. In summary, there is great need for new ideas on a possible etiopathogenesis of SNHL and the NFкB theory is tempting to follow. 
R. Maire: The authors made an excellent and exhaustive critical review of the different hypotheses proposed to explain the etiology and pathogenesis of idiopathic SSHL. Especially, they focused on the viral hypothesis which is severely questioned. As a new postulate, they proposed and discussed the pathophysiological concept of abnormal cellular stress response, which may be a promising alternative to explain SD.

C.A. Oliveira: This is a very thorough review of the current knowledge about the etiology of SSHL. At least two etiologies seem to be the cause of some but not all SSHL cases: viral and vascular etiologies. Other possible etiologies have less reliable evidence to support them. It seems to me that at least one statement could have been made from this review: SSHL seems to have multiple causes. Two are reasonably acceptable at least in some cases: viral and vascular causes.

I. Pyykkö: The paper describes an interesting mechanism producing apoptosis in the inner ear by activating the NFкB pathway, but the actual mechanism was not explained. No evidence for activation of this mechanism was demonstrated either. Therefore, no argument for or against it can be presented. An argument against viral infection presented in this paper was that Pitkäranta and Julkunen did not find cytokine activation that commonly occurs in general viral infection. Therefore, the 'viral theory' would be unlikely. The clinical evidence shows that it is very unlikely that in a local activation of viral replication the body cytokine responses would be significantly affected. 